\title{
A Theoretical Investigation of Selenite(IV) and Hydrogenselenite(IV) Structures. Comparison with Sulfites and Tellurites
}

\author{
Ann Strömberg, ${ }^{a}$ Dan Strömberg, ${ }^{\text {a }}$ Ulf Wahlgren, ${ }^{\text {a }}$ Saila Karvinen ${ }^{b}$ \\ and Lauri Niinistö
}

a Department of Inorganic Chemistry, Chalmers University of Technology and the University of Göteborg,

S-41296 Göteborg, Sweden and ' ${ }^{b}$ Department of Chemistry, Helsinki University of Technology,

SF-02150 Espoo, Finland

\begin{abstract}
Strömberg, A., Strömberg, D., Wahlgren, U., Karvinen, S. and Niinistö, L., 1986. A Theoretical Investigation of Selenite(IV) and Hydrogenselenite(IV) Structures. Comparison with Sulfites and Tellurites. - Acta Chem. Scand. A 40: 601-606.

As part of a theoretical investigation of the oxygen coordination in chalcogen(IV) compounds, the protonation of the selenite ion was studied. RHF-SCF calculations using the frozen-orbital ECP method are presented for $\mathrm{SeO}_{2}, \mathrm{SeO}_{3}{ }^{2-}$, $\mathrm{HSeO}_{3}{ }^{-}$and $\mathrm{SeO}_{2} \mathrm{OH}^{-}$. Geometry optimizations were performed on all the molecules and comparison made with earlier studies on similar sulfite and tellurite compounds. The $\mathrm{SeO}_{2} \mathrm{OH}^{-}$isomer was found to be more stable than $\mathrm{HSeO}_{3}^{-}$by $30 \mathrm{kcal} \mathrm{mol}^{-1}$, and thus the selenites resemble more closely the tellurites than the sulfites. The calculated geometries of $\mathrm{SeO}_{3}{ }^{2-}$ and $\mathrm{SeO}_{2} \mathrm{OH}^{-}$agreed well with those experimentally determined.
\end{abstract}

A theoretical study of bonding relations in tellurium(IV) oxygen compounds has been initiated $^{1}$ in order to investigate the great diversity of $\mathrm{Te}-\mathrm{O}$ bond lengths and with them the large variety of coordinations found in tellurite structures (see Ref. 2 and references therein). Comparison has been made with MO calculations on corresponding sulfur(IV) compounds which show a quite different coordination behaviour in crystal structures. In the tellurium compounds, the tellurites couple via $\mathrm{Te}-\mathrm{O}-\mathrm{Te}-\mathrm{O} \ldots$ bridges, thus forming chains, sheets or networks. Sulfur, however, has a tendency for S-S bonding, as demonstrated in the structure of $\mathrm{S}_{2} \mathrm{O}_{5}{ }^{2-}{ }^{3}$.

As a first model of the coordination behaviour, the protonation of the $\mathrm{XO}_{3}{ }^{2-}$ ions, where $\mathrm{X}$ is $\mathrm{S}$, $\mathrm{Se}$ or $\mathrm{Te}$, has been used. The two possible isomers, $\mathrm{HXO}_{3}^{-}$and $\mathrm{XO}_{2} \mathrm{OH}^{-}$, are shown in Fig. 1. The proton can be thought of here as a simple model for a counterion or a sulfur, selenium or tellurium from a neighbouring group. The difference in total energy between the isomers and the geometric variations generated gave indications
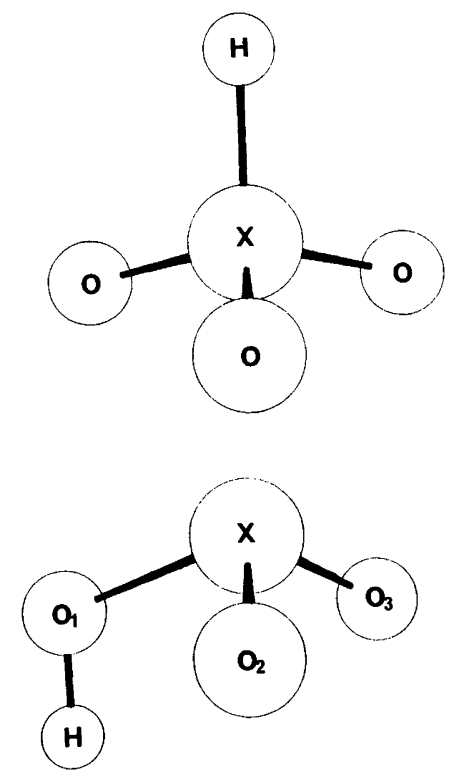

Fig. 1. The molecular structure of the isomers $\mathrm{HXO}_{3}^{-}$ and $\mathrm{XO}_{2} \mathrm{OH}^{-}$. 
STRÖMBERG ET AL.

Table 1. The valence basis set and ECP parameters for selenium.

\begin{tabular}{|c|c|c|c|c|}
\hline $\begin{array}{l}s \\
\text { exponent }\end{array}$ & $\begin{array}{l}p \\
\text { exponent }\end{array}$ & $\begin{array}{l}d \\
\text { exponent }\end{array}$ & & coefficient \\
\hline $\begin{array}{l}14.203858 \\
4.3807845 \\
1.8656604 \\
0.35967956 \\
0.13967956 \\
0.0521\end{array}$ & $\begin{array}{l}16.844137 \\
5.8445460 \\
2.1416818 \\
0.46904735 \\
0.14011554\end{array}$ & $\begin{array}{l}24.240019 \\
6.6631075 \\
2.1782858 \\
0.85555199 \\
0.29168913\end{array}$ & & $\begin{array}{l}0.21137256 \\
0.5103780 \\
0.4197939 \\
1.0 \\
1.0\end{array}$ \\
\hline \multicolumn{5}{|c|}{ ECP parameters: ${ }^{a}$} \\
\hline \begin{tabular}{cc}
$Z_{\text {eff }}$ & \multicolumn{1}{c}{24.0} \\
$B_{1 s}$ & 460.84 \\
$B_{2 s}$ & 60.64 \\
$B_{2 p}$ & 54.23
\end{tabular} & $\begin{array}{l}\alpha_{1} \\
\alpha_{2} \\
\alpha_{3} \\
\alpha_{4} \\
\alpha_{5} \\
\alpha_{6}\end{array}$ & $\begin{array}{r}112.0647 \\
371.0827 \\
28.5614 \\
6480.7652 \\
102.5155 \\
10.5463\end{array}$ & $\begin{array}{l}A_{1} \\
A_{2} \\
A_{3} \\
A_{4} \\
A_{5} \\
A_{6}\end{array}$ & $\begin{array}{l}0.055399 \\
0.245918 \\
0.029353 \\
7.0307 \\
0.9758 \\
0.2262\end{array}$ \\
\hline
\end{tabular}

Notation as in Ref. 10.

of the coordination behaviour of the various chalcogenite(IV) ions. The results also gave a measure of the stability and geometry of the protonated species whose existence and molecular structures are far from clear.

In the studies of tellurites and sulfites, ${ }^{1} \mathrm{HSO}_{3}{ }^{-}$ and $\mathrm{SO}_{2} \mathrm{OH}^{-}$were found to be of almost equal energy, whereas $\mathrm{TeO}_{2} \mathrm{OH}^{-}$, on the other hand, was calculated to be more stable than $\mathrm{HTeO}_{3}{ }^{-}$by as much as $47 \mathrm{kcal} \mathrm{mol}^{-1}$. Tellurites thus clearly prefer hydrogen coordination on the oxygen, and it is reasonable to conclude that if either of the hydrogentellurite isomers exists in solution it is $\mathrm{TeO}_{2} \mathrm{OH}^{-}$. The only $\mathrm{HXO}_{3}{ }^{-}$ion isolated and experimentally characterized is $\mathrm{HSO}_{3}^{-}$, in e.g. $\mathrm{CsHSO}_{3},{ }^{4}$ and the calculated geometry for $\mathrm{HSO}_{3}{ }^{-}$ (with the inclusion of the crystal field) ${ }^{5}$ agrees well with experiment. In the case of $\mathrm{XO}_{2} \mathrm{OH}^{-}$, it appears that no sulfur or tellurium compound of the kind has ever been isolated.

The hydrogenselenite ion, $\mathrm{SeO}_{2} \mathrm{OH}^{-}$, is well known from many single crystal structures (see Refs. 6, 7 and references therein), but $\mathrm{HSeO}_{3}{ }^{-}$ has never been found. The selenites thus provide an opportunity for testing the validity of the computed geometries of the unknown sulfite and tellurite species protonated on oxygen. The question also arises as to whether the selenites have an intermediate position or whether their behaviour is closer to that of either sulfites or tellurites. Ex- perimentally, no selenite structures with $\mathrm{Se}-\mathrm{Se}$ bonds have been found nor any with such large irregularities in $\mathrm{X}-\mathrm{O}$ bonds as in the case of the tellurites. We have therefore undertaken this theoretical study of the selenites $\mathrm{SeO}_{3}{ }^{2-}, \mathrm{HSeO}_{3}{ }^{-}$ and $\mathrm{SeO}_{2} \mathrm{OH}^{-}$.

\section{Computational details}

The calculations were accomplished at the RHFSCF level using the Molecule-Alchemy programs. The RHF approximation has been shown in the earlier sulfite and tellurite studies ${ }^{1,5,8}$ to be valid for the types of compounds involved in this study.

The number of electrons in selenium is large but only a few of them are actually involved in the formation of bonds. This fact is utilized in the Effective Core Potential (ECP) method, which substantially reduces the computing time and the resources needed in calculations on systems like the selenites. In the frozen-orbital ECP method ${ }^{9}$ employed here, the inner core orbitals of selenium, $1 s-2 p$, were replaced by a local potential. The parameters of this simple potential, which were determined in calculations on the atom, are presented in Table 1 . In the SCF calculations, the outermost core shell orbitals, $3 s-3 d$, were kept in their atomic shape as frozen orbitals (they were not varied). 
Table 2. Caiculated bond distances $(\AA)$, angles $\left(^{\circ}\right)$ and charges (a.u.) $)^{a}$ for the $\mathrm{XO}_{3}{ }^{2-}, \mathrm{HXO}_{3}{ }^{-}, \mathrm{XO}_{2} \mathrm{OH}^{-}$and $\mathrm{XO}_{2}$ compounds ( $\mathrm{X}=\mathrm{S}$, Se or Te).

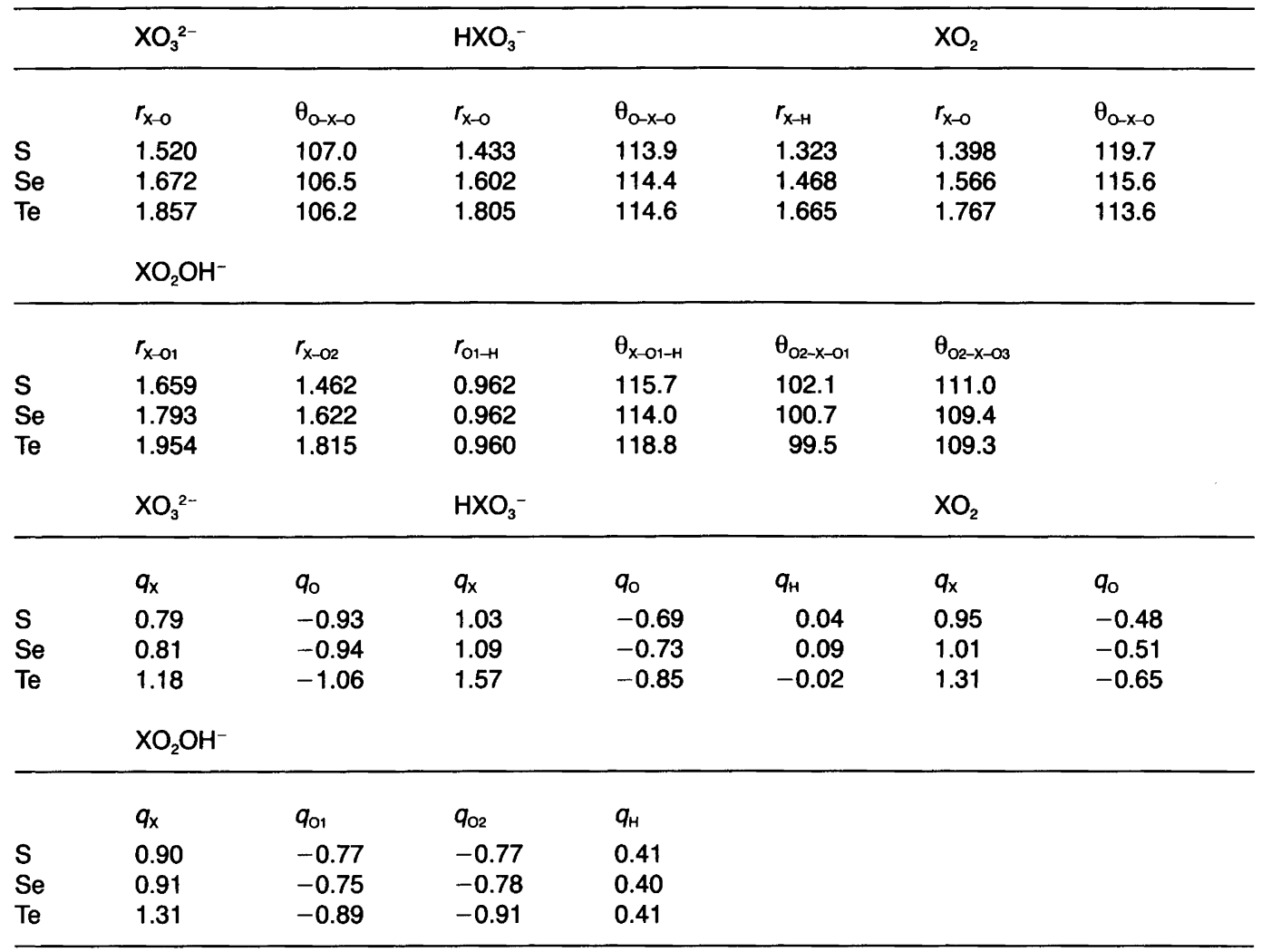

${ }^{a}$ Charges are obtained from a Mulliken population analysis.

The number of basis functions in the basis set was reduced: thirteen $s$, nine $p$ and six $d$ were cut down to six $s$, five $p$ and five $d$ gaussian functions. The all-electron basis set optimized $(13,9,6)$ gave a total energy of -2399.6027 a.u. Some $d$ exponents were reoptimized, on $\mathrm{Se}^{+} s^{2} p^{2} d^{1}$, in order to be able to describe a $4 d$ orbital of proper shape. This was done in accordance with earlier findings in the sulfite system, ${ }^{8}$ where $d$ exponents suitable for describing a proper $3 d$ orbital are needed for a good description of the $\mathrm{S}-\mathrm{O}$ bond distances of the ions. The valence $s, p$ basis set (see Table 1) was obtained by deleting the innermost functions. One diffuse $s$ exponent (0.0521) was also added. The three innermost $d$ functions were replaced by two, by a least-squares procedure. These five resulting $d$ functions were further con- tracted to three. The frozen orbitals were expressed in the smaller, reduced basis set, and their coefficients are available from the authors upon request.

The nine $s$-, five $p$-type basis set of Huzinaga ${ }^{10}$ for oxygen was contracted to four $s$ and three $p$, and one diffuse $p$ function (exponent 0.64 ) was added in order to better describe the negative oxygen. For hydrogen, the three $s$ primitive set of van Duijnevelt, ${ }^{11}$ contracted to two $s$ functions, was used. Details of the basis sets and ECP parameters used in the earlier sulfite and tellurite calculations, results from which are also given in this article, are presented in Refs. 1 and 8.

The geometries of all the ions except $\mathrm{SeO}_{2} \mathrm{OH}^{-}$ were found using ordinary grid techniques. Due to the large number of degrees of freedom in the 
latter ion, force-field methods ${ }^{12}$ modified for ECP calculations ${ }^{13}$ had to be employed. The three-fold axis in $\mathrm{SeO}_{3}{ }^{2-}$ and $\mathrm{HSeO}_{3}{ }^{-}$, and the mirror plane containing the $\mathrm{Se}-\mathrm{O}-\mathrm{H}$ bonds in $\mathrm{Se}-$ $\mathrm{O}_{2} \mathrm{OH}^{-}$were retained while varying the geometry.

In the calculations on $\mathrm{K}_{2} \mathrm{SeO}_{3}$, the inclusion of the electrostatic crystal field was made using the Ewald technique. ${ }^{14}$

\section{Results and discussion}

$\mathrm{SeO}_{2}$ all-electron compared with ECP. The frozen-orbital ECP method has earlier been shown to yield quantitatively reliable results for compounds of both transition metals and main group elements, ${ }^{9,15}$ i.e. it can reproduce all-electron ( $a b$ initio) calculations quite well. As an illustration of this, we performed both all-electron and frozen-orbital ECP calculations on $\mathrm{SeO}_{2}$. The basis set for oxygen was the same in both cases, but for selenium the $13,9,6$ basis set was, of course, used in the all-electron case. The ECP results for the geometry, $r_{\mathrm{Se}-\mathrm{O}}=1.566 \AA$ and $\theta_{\mathrm{O}-\mathrm{Se}-\mathrm{O}}=115.6^{\circ}$, were in good agreement with those of the allelectron calculation: $1.576 \AA$ and $115.0^{\circ}$. Both bond distances are much shorter than the experimental one, which is $1.607 \pm 0.0006 \AA$ in the gas phase. ${ }^{16}$ This discrepancy is roughly the same in $\mathrm{SO}_{2}$ and $\mathrm{TeO}_{2}$ and is due to the fact that electron configurations other than that of the HartreeFock approximation are of importance in describing these systems. These $\mathrm{MC}$ effects in $\mathrm{XO}_{2}$ will be the subject of another study.

The selenite ion. The doubly negatively charged selenite ion, $\mathrm{SeO}_{3}{ }^{2-}$, is not stable in vacuum but has been experimentally characterized in crystal structures. The theoretically obtained geometry, $1.672 \AA$ and $106.5^{\circ}$ (see Table 2), cannot, therefore, be compared directly with experiment. However, the single-crystal structure of $\mathrm{K}_{2} \mathrm{SeO}_{3}$, which has only recently been solved, ${ }^{17}$ may be considered to represent pure ionic character and thus offers a possibility of comparison. The inclusion of the electrostatic field, generated by the surroundings of the ion in the crystal, gave a lengthening of the Se-O bond by $0.01 \AA$ to 1.683 $\AA$ and an angle of $103.8^{\circ}$. These compare well with the experimentally determined values of $1.672(1) \AA$ and $102.90(2)^{\circ}$ in the crystal. This magnitude of the "field effect" should be borne in mind in the following discussion of the hydro-

Table 3. Differences in calculated bond lengths $(\AA)$ between the different sulfite, selenite and tellurite compounds, respectively.

\begin{tabular}{|c|c|c|c|}
\hline & $\begin{array}{c}\Delta r_{\mathrm{X}-\mathrm{O}_{1}} \\
\left(\mathrm{HXO}_{3}{ }^{-}-\mathrm{XO}_{2} \mathrm{OH}^{-}\right)\end{array}$ & $\left(\mathrm{HXO}_{3}^{-}-\stackrel{\Delta r_{\mathrm{X}-\mathrm{O} 2}}{\left.-\mathrm{XO}_{2} \mathrm{OH}^{-}\right)}\right.$ & $\left(\mathrm{XO}_{3}^{2-}-\stackrel{\Delta r_{\mathrm{X}-01}}{\left.-\mathrm{XO}_{2} \mathrm{OH}^{-}\right)}\right.$ \\
\hline $\begin{array}{l}\text { S } \\
\text { Se } \\
\text { Te }\end{array}$ & $\begin{array}{c}-0.226 \\
-0.191 \\
-0.146 \\
\\
\Delta r_{\mathrm{XOO2}} \\
\left(\mathrm{XO}_{2}-\mathrm{XO}_{2} \mathrm{OH}^{-}\right)\end{array}$ & $\begin{array}{c}-0.029 \\
-0.020 \\
-0.010 \\
\Delta r_{\mathrm{X}-02} \\
\left(\mathrm{XO}_{3}^{2-}-\mathrm{XO}_{2} \mathrm{OH}^{-}\right)\end{array}$ & $\begin{array}{c}-0.139 \\
-0.121 \\
-0.097 \\
\Delta r_{\mathrm{x}-0} \\
\left(\mathrm{XO}_{3}^{2-}-\mathrm{HXO}_{3}^{-}\right)\end{array}$ \\
\hline $\begin{array}{l}\text { S } \\
\text { Se } \\
\text { Te }\end{array}$ & $\begin{array}{c}-0.064 \\
-0.056 \\
-0.048 \\
\Delta r_{\mathrm{Xo}} \\
\left(\mathrm{XO}_{2}-\mathrm{HXO}_{3}^{-}\right)\end{array}$ & $\begin{array}{c}0.058 \\
0.050 \\
0.042 \\
\Delta r_{\mathrm{X}-0} \\
\left(\mathrm{XO}_{2}-\mathrm{XO}_{3}{ }^{2-}\right)\end{array}$ & $\begin{array}{l}0.087 \\
0.070 \\
0.052\end{array}$ \\
\hline $\begin{array}{l}\text { S } \\
\text { Se } \\
\text { Te }\end{array}$ & $\begin{array}{l}-0.035 \\
-0.036 \\
-0.038\end{array}$ & $\begin{array}{l}0.122 \\
0.106 \\
0.090\end{array}$ & \\
\hline
\end{tabular}


genselenites, for which only structures too elaborate for calculations exist.

The hydrogenselenites. In Table 2, the results from the geometric optimization of $\mathrm{HSeO}_{3}{ }^{-}$and $\mathrm{SeO}_{2} \mathrm{OH}^{-}$are presented. The earlier results ${ }^{1}$ for the analogous sulfur and tellurium compounds are also given for comparison. The total energies are not given, since energies using an ECP are not directly comparable with all-electron values.

The difference in total energy between the two isomers, $\mathrm{HSeO}_{3}{ }^{-}$and $\mathrm{SeO}_{2} \mathrm{OH}^{-}$, was found to be $31 \mathrm{kcal} \mathrm{mol}^{-1}$, with the latter ion more stable. Corresponding values for the analogous sulfur and tellurium isomers are -3 and $47 \mathrm{kcal} \mathrm{mol}^{-1}$, respectively. ${ }^{1}$ The energy difference is so large that even if correlation and solvation effects are substantial, the $\mathrm{HSeO}_{3}{ }^{-}$isomer is not likely to be found in solution. With respect to this energy difference for the isomers, the selenites seem to resemble the tellurites more than the sulfites. $\mathrm{SeO}_{2} \mathrm{OH}^{-}$has been identified experimentally, and in view of the correspondence with the hydrogenselenites, it is reasonable to assume that if either of the isomers $\mathrm{HTeO}_{3}{ }^{-}$or $\mathrm{TeO}_{2} \mathrm{OH}^{-}$exists it should be the latter.

The geometry of $\mathrm{SeO}_{2} \mathrm{OH}^{-}$compares well with the experimental values in e.g. $\mathrm{LiHSeO}_{3},{ }^{18}$ the experimental $\mathrm{Se}-\mathrm{OH}$ bond length being $1.792(2)$ $\AA$ and the computed $1.793 \AA$. The average $\mathrm{Se}-\mathrm{O}$ bond length (the $\mathrm{SeO}_{2} \mathrm{OH}^{-}$ion is slightly distorted and contains no mirror plane) is $1.66 \AA$ in the structure but $1.62 \AA$ in our calculations. The longer $\mathrm{Se}-\mathrm{O}$ bond found in the crystal structure is probably due to the weak interaction between $\mathrm{Li}^{+}$and oxygen, since the $\mathrm{Li}-\mathrm{O}$ distance is only about $2 \AA$, and to hydrogen bonding. The calculations have been made without the inclusion of the surrounding field, the crystal structure of $\mathrm{LiHSeO}_{3}$ being too complicated to allow an electrostatic crystal field calculation. However, as mentioned in the previous section, such an electrostatic field would lengthen the $\mathrm{Se}-\mathrm{O}$ bond by only $0.01 \AA$. The angles $98.29(9), 101.21(9)$ and $103.87(9)^{\circ}$ also compare fairly well with the calculated ones: $100.7^{\circ}$ and $109.4^{\circ}$. This agreement for $\mathrm{SeO}_{2} \mathrm{OH}^{-}$makes the calculated geometries of $\mathrm{SO}_{2} \mathrm{OH}^{-}$and $\mathrm{TeO}_{2} \mathrm{OH}^{-}$(see Table 2) appear plausible.

Comparison can also be made with the structure of $\mathrm{Cu}\left(\mathrm{HSeO}_{3}\right)_{2} \cdot \mathrm{H}_{2} \mathrm{O},{ }^{7}$ where the observed $\mathrm{Se}-\mathrm{O}$ bond lengths are 1.678(4) and 1.673(4) $\AA$, while the $\mathrm{Se}-\mathrm{OH}$ bond is $0.1 \AA$ longer, i.e. $1.773(5) \AA$. For tris(hydrogenselenite)salts, where a large number of alkali and ammonium selenite structures are known, the mean values are 1.65 and $1.75 \AA$ for the $\mathrm{Se}-\mathrm{O}$ and $\mathrm{Se}-\mathrm{OH}$ bonds, respectively. ${ }^{19}$

The calculated changes in geometries upon protonation are shown in Table 3. The largest effects are seen within the sulfite compounds and the smallest within the tellurites. Here, the selenites clearly have a middle position. The overall spread in $r_{\mathrm{x}-\mathrm{O}}$ was quite large and a comparison with estimated single- and double-bond lengths might be useful.

The single-bond lengths for $\mathrm{X}-\mathrm{O}(\mathrm{X}=\mathrm{S}, \mathrm{Se}, \mathrm{Te})$ are, according to Pauling, ${ }^{20} 1.70,1.83$ and 2.03 $\AA$, respectively; the corresponding double-bond lengths are $1.50,1.63$ and $1.83 \AA$. The calculated $\mathrm{X}-\mathrm{O}$ bond length in $\mathrm{XO}_{3}{ }^{2-}$ is generally slightly greater than the double-bond length given by Pauling, but in $\mathrm{HXO}_{3}^{-}$and $\mathrm{XO}_{2}$ it is less. In $\mathrm{XO}_{2} \mathrm{OH}^{-}$, the long $\mathrm{X}-\mathrm{OH}$ bond is significantly shorter than the single bond. The deviations from Pauling's values are generally largest for the sulfites. There is one exception: the calculated $\mathrm{Te}-\mathrm{OH}$ bond length in $\mathrm{TeO}_{2} \mathrm{OH}^{-}$is substantially less than for a single bond. The differences in $\mathrm{X}-\mathrm{O}$ bond lengths, both for double and single bonds, between sulfur, selenium and tellurium are, according to Pauling, 0.13 and $0.20 \AA$, indicating that selenium should geometrically resemble sulfur more closely than tellurium. However, our results put selenium roughly midway between sulfur and tellurium, as seen in Table 3 .

The population analysis revealed a great difference in the charge distributions in the sulfites, selenites and tellurites, the bonds of the tellurites being much more polar than those of the sulfites and selenites. The energy differences between protonated isomers of the three species place the selenites closer to tellurites than to sulfites. This might seem contradictory to the population analysis result, but it must, however, be borne in mind that the protonation energy depends on several factors not apparent in the population analysis (relaxation etc.). The systems are, however, similar enough for a comparison of Mulliken populations to be relevant. The tellurium atom in $\mathrm{TeO}_{3}{ }^{2-}$, being thoroughly positive, will easily coordinate to the negative oxygen of another tellurite group. In the selenite case, $\mathrm{SeO}_{3}{ }^{2-}$, with its less electropositive selenium, will have 
greater competition from a proton for the oxygen sites on another selenite ion. This may throw some light on the question of why tellurites easily form sheets and chains with $\mathrm{Te}-\mathrm{O}-\mathrm{Te}$ bonds, whereas the selenites also crystallize often as hydrogenselenites with large hydrogen-bonded sheets or chain structures, or as small units as in $\mathrm{Se}_{2} \mathrm{O}_{5}{ }^{2-} \cdot{ }^{21}$

\section{Concluding remarks}

The $\mathrm{SeO}_{3}{ }^{2-}$ ion, like $\mathrm{TeO}_{3}{ }^{2-}$ prefers protonation on the oxygens, and the geometry of $\mathrm{SeO}_{2} \mathrm{OH}^{-}$ compares quite well with the experimentally determined one in $\mathrm{LiHSeO}_{3}$. The previously calculated geometry of the unknown $\mathrm{TeO}_{2} \mathrm{OH}^{-}$ion thus appears reasonable. Since the only hydrogenselenite isomer isolated is the one with the hydrogen on the oxygen, these calculations strongly support the earlier results indicating that it is $\mathrm{TeO}_{2} \mathrm{OH}^{-}$and not $\mathrm{HTeO}_{3}{ }^{-}$which is most likely to occur if a hydrogen tellurite ion exists.

The calculated relative charge distributions in $\mathrm{XO}_{3}{ }^{2-}$ ions can also be used to some extent to clarify their differences in coordination behaviour. However, a more thorough study of the formation of sheet and chain structures of tellurite(IV) is needed in order to understand better the different behaviour of sulfites, selenites and tellurites. Such a study is in progress.

\section{References}

1. Strömberg, A., Wahlgren, U. and Lindqvist, O. Chem. Phys. 100 (1985) 229.
2. Lindqvist, O. Thesis, University of Göteborg, Göteborg 1973.

3. Baggio, S. Acta Crystallogr.Sect. B 27 (1971) 517.

4. Johansson, L.-G., Lindqvist, O. and Vannerberg, N.-G. Acta Crystallogr.Sect. B36 (1980) 2523.

5. Strömberg, A., Gropen, O., Wahlgren, U. and Lindqvist, O. Inorg. Chem. 22 (1983) 1129.

6. Valkonen, J. and Leskelä, M. Acta Crystallogr. Sect. B 34 (1978) 1323.

7. Hiltunen, L., Leskelä, M., Niinistö, L. and Tammenmaa, M. Acta Chem. Scand. Ser. A39 (1985) 809.

8. Strömberg, A., Wahlgren, U., Pettersson, L. and Siegbahn, P. E. M. Chem. Phys. 89 (1984) 323.

9. Pettersson, L. G. M., Wahlgren, U. and Gropen, O. Chem. Phys. 80 (1983) 7.

10. Huzinaga, S. Internal Report, University of Alberta, Edmonton 1971.

11. van Duijneveldt, F. B. IBM Research Report RJ 945 (1971).

12. Sæbö, S. Internal Report, University of Oslo, Oslo 1979.

13. Broch Mathisen, $\mathrm{K}$. and Strömberg, A. Internal Report, University of Tromsö, Tromsö 1983.

14. Almlöf, J. and Wahlgren, U. Theor. Chim. Acta 28 (1973) 161.

15. Strömberg, A., Gropen, O. and Wahlgren, U. J. Chem. Phys. 80 (1984) 1593.

16. Takeo, H., Hirota, E. and Morino, Y. J. Mol. Spectrosc. 34 (1970) 370.

17. Eriksson, S. and Helander, P. To be published.

18. Chomnilpan, S. and Liminga, R. Acta Crystallogr. Sect. B35 (1979) 3011.

19. Chomnilpan, S., Tellgren, R. and Liminga, R. Acta Crystallogr.Sect. B 34 (1978) 373.

20. Pauling, L. The Nature of the Chemical Bond, 3rd ed., Cornell University Press, Ithaca, NY 1960.

21. Chomnilpan, S. Acta Crystallogr.Sect. B 36 (1980) 675.

Received June 13, 1986. 